\section{Synthesis of Two Isomeric bis-Thiocamphors}

Is continuation of his researches on thiocamphor ${ }^{1}$ reported in this journal, and also published in the Journal of the Indian Chemical Society, Mr. D. C. Sen, working in my laboratory, has recently made some interesting observations which, with his views concerning the constitution of the compounds isolated, are reported below.

Bis-thiocamphor has been synthesized by the action of iodine on the sodio derivative of thiocamphor. It may be represented by either (A) or (B).

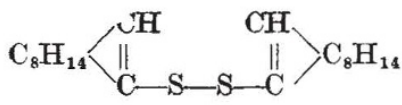

(A)

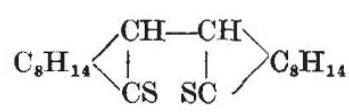

(B)

It has not been possible to synthesize this compound by Oddo's method ${ }^{2}$ of synthesis of bis-camphor, namely, by the action of sodium or magnesium on $\beta$-bromocamphor, as $\beta$-bromothiocamphor could not be isolated in the pure state. Incidentally, the synthesis of bis-camphor by this method was also tried, but it resulted in the formation of $\beta$-iodo. camphor instead of bis-camphor. Bis-thiocamphor has been prepared by the above method in two stereoisomeric forms ( $l$ - and $d l-$ ) from $l$-thiocamphor and $d l$-thiocamphor respectively.

$d l$-Bis-thiocamphor, m.p. $164^{\circ}$, forms a dioxine, m.p. $199^{\circ}(d)$ and an azine, m.p. $176^{\circ}$, whereas $l$-bis. thiocamphor, m.p. $180^{\circ}$, also forms an azine, m.p. $200^{\circ}$, under similar conditions. These facts, along with the analytical and molecular weight data of the two bis-thiocamphors and their derivatives, lead to the conclusion that they contain two $\mathrm{C}: \mathrm{S}$ groups, and that they are 1:4-dithioketones, and have the formula (B). The dioxines and the azines should therefore be represented by the structures (C) and (D) respectively.<smiles>CCCCCCC(=O)C(O)C(=O)O</smiles>

(C)

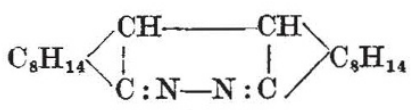

(D)

On reduction with aluminium amalgam in moist ethereal solution, $d l$-bis-thiocamphor forms $d l$-bisthioborneol, m.p. $148^{\circ}$, which decolorizes iodine and forms a yellow lead salt.

l-Bis-thiocamphor has a very high molecular rotation $[M]_{D}^{30^{\circ}}=-1109.5$ in benzene solution, whereas the molecular rotation of $l$-thiocamphor is $[M]_{D}^{30^{\circ}}=-41.3$ in the same solvent, and under similar conditions. This high exaltation in optical activity may be attributed to the presence of a potential conjugated system in bis-thiocamphor, which may be effective both in the thio- and thiol- phases.

Studies in absorption spectra in the visible region of bis-thiocamphor at different dilutions and the comparison of these with those of thiofenchone and thiocamphor have given interesting results. It has been noticed that a $\mathbf{5 \cdot 4}$ per cent solution of bisthiocamphor in benzene manifests a characteristic absorption band between $5270 \mathrm{~A}$. and $4530 \mathrm{~A}$., and that with dilution this band becomes shorter, and at $2 \cdot 7$ per cent concentration it gives a very short band, having the centre at 4950 A. Similar bands have also been observed in the case of $l$-thiocamphor and $d$-thiofenchone. This selective absorption band is therefore a characteristic property of the $\mathrm{C}: \mathrm{S}$ group in cyclic thioketones, which is definitely chromophoric.

Further work in this line, which is in progress, will be published in detail in due course in the Journal of the Indian Chemical Society.

Palit Laboratory,

P. C. RÂY.

$$
\begin{gathered}
\text { University College of Science and } \\
\text { Technology, } \\
\text { Calcutta. }
\end{gathered}
$$

1 Nature, 134, 1010 (1934); J. Indian Chem. Soc., 12, 647, 751 (1935). (1935).
(1904).

\section{Non-Existence of Multiplanar Cyclohexane Rings}

THe work done by us, so far, has shown that it is possible to isolate only two forms of 4-methyl-, 3-methyl- and 2-methylcyclohexane-1. carboxy-1-acetic acids ${ }^{1}$ and one form of $3: 3$ dimethyleyclohexane-1-carboxy-1-acetic acid ${ }^{2}$. In order to get more evidence on the point of the con. figuration of the cyclohexane ring, we have now synthesized 4:4-dimethylcyclohexane-1-carboxy-1acetic acid and 4:4-dimethyleyclohexane-1:1-diacetic acid from 4 : 4-dimethylcyclohexanone. Each one of them is found to exist in one form only, thus supporting the uniplanar structure of the cyclohexane ring. The work is not yet complete, but this notice has been necessary in view of the recent publication of Miller and Roger Adams on the same subject ${ }^{3}$. The full details of the work will be published in due course.
Department of Chemistry, Muslim University, Aligarh, India. August 23.

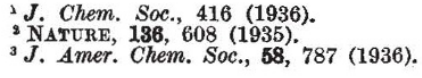

3. Amer. Chem. Soc., 58, 787 (1936).

R. D. DESAI.

R. F. HUNTER.

\title{
Normal Erosion as a Factor in Soil Profile Development
}

In Nature of June 6, Prof. G. W. Robinson directs attention to the effects of lateral transport of surface soil material, moved in the course of ordinary slow denudation, on certain soils in Wales. Erosive processes of this kind not only modify the develop. ment of particular soil profiles, but also may be found governing the zonation of soil types over wide areas. I offer an example from tropical semi-arid country.

The diagram (Fig. 1) represents, with the horizontal scale much compressed, a residual granite hillock and the soils around it, in the plateau region south of Lake Victoria. Primary soil substance is made among the rocks from the products of mechanical 